\title{
Causes of diseases of the digestive system of the young cattle
}

\author{
Irina Kondakova ${ }^{1,}$, , Ekaterina Vologzhanina $^{1}$, Julia Lomova $^{1}$, and Nadezhda Kryuchkova ${ }^{1}$ \\ ${ }^{1}$ Rybinsk State Aviation Technical University named after P. A. Solovyov, Ryazan, Russian \\ Federation
}

\begin{abstract}
Monitoring of diseases of the digestive system of young cattle was carried out in agricultural enterprises of Ryazan region. The conditions of animal management were studied. The diagnosis of infectious diseases of the digestive system of calves was established taking into consideration the results of epizootological data, clinical signs, pathological anatomical picture on the basis of bacteriological, mycological, mycotoxicological, copro-ovoscopic and larvoscopic studies. Of the total number of 168,572 calves, the number of animals with diseases of the digestive system was $28,32-44,19 \%$. Among mixed invasions in young cattle up to 6-8 months of age, Ostertagias were recorded in combination with Chabertias and esophagostomas. Calves at the age of 2-3 months often had additional eimeriosis. Among infectious diseases of young cattle, diseases of bacterial etiology amounted to $89,69-94,11 \%(50,98 \%$ - colibacillosis, $11,92 \%$ proteus infection, $4,95 \%$ - salmonellosis, $4,53 \%$ - pasteurelliosis, $5,93 \%$ pseudomonosis, $10,51 \%$ - streptococcosis, $2,10 \%$ - staphylococcosis, $0,47 \%$ - klebsiellosis). Laboratory tests of feed revealed microscopic fungi, but no mycotoxins were found. Mycotoxicosis in animals were not registered.
\end{abstract}

\section{Introduction}

In modern conditions of intensive technology of industrial milk production, the main thing is to raise healthy young animals, because obtaining an inherited level of milk production is possible only from a healthy animal. The health of young animals depends on factors of the internal and external environment.

Parasitism of various types of helminths, the simplest among farm animals, is often recorded at enterprises of the agro-industrial complex. In this case, the pathological process can be aggravated by both viral and bacterial microflora, which ultimately leads to a decrease in the growth and development of animals, loss of body weight and the death of young animals. Weakened calves having cute gastrointestinal diseases are born from pregnant animals infected with nematodes.

As a rule, adult animals have nematodes manifested in a subclinical form. Strongylata larvae can be in a state of hypobiosis for a long time, not showing activity. When the

\footnotetext{
${ }^{*}$ Corresponding author: irina20175@mail.ru
} 
immune status of the animal changes, caused by unfavorable environmental conditions or inadequate feeding, active development of larvae occurs and an increase in invasion is observed. In an adult livestock, the clinical manifestation of the disease in different seasons of the year can be promoted by viral, bacterial infections and protozoal diseases.

On average $20-25 \%$ of the Russian cattle is infected with strongylatosis of the gastrointestinal tract. Cows in the Non-Black Earth Zone more often have stomach worms, nematode worms, Bunostomum trigonocephalum, esophagostomas and Chabertia. In the south of the country, the number of animals being sick with strongylatosis is higher, mainly nematode worms and Chabertias. On the territory of the North Caucasus, helminthiases among cattle are noted throughout the year, regardless of natural and climatic zones, among different age groups, while strongylatosis of the gastrointestinal tract, as a rule, is always accompanied by parasitizing Fasciolas, Dicrocoelia, larval stages of Echinococcus or Eimeria in animals [1-4].

According to some authors, strongylatosis of the gastrointestinal tract of the cattle is common in various farms regardless of ownership (joint-stock farms: EI - 54,2\%, II - 224 species; farms: EI - 55,3\%, II - 247 species; peasant farms: EI - 64,7\%, II - 278 species of Strongylata eggs) [1, 6-8].

The greatest infestation of animals by nematodes is observed on low-lying pastures, which are sufficiently humid. Animals grazing on dry meadows are less susceptible to infection [1, 6-8].

The greatest number of cows infected with strongylatosis of the gastrointestinal tract is recorded in summer and autumn months. In winter, the infection gradually decreases, and by spring it begins to grow again.

When parasitic diseases in an animal, a response occurs and immunity develops. Unfortunately, when helminthiasis, precipitating, agglutinating immunoglobulins and phagocytosis are powerless. The main components of anthelminthic immunity are eosinophils, tissue basophils, macrophages and T-, B-lymphocytes. The survival rate of Strongylatas of the gastrointestinal tract is significantly reduced in the adult cattle as compared with young animals, the reproductive ability of females decreases, and life expectancy is reduced. Diseases of newborn calves, accompanied by diarrhea, prevail over other diseases characteristic of this age of young farm animals. Changing external environmental conditions determine the variety of causal associations of diseases of the digestive system.

The etiological structure of diseases of the digestive system of calves is complex and diverse. The causative agents of diseases are well known and easily identified [5-10].

Thus, diseases of the gastrointestinal tract have the largest percentage of all diseases of calves, that causes significant economic damage associated with high mortality and treatment costs. It should be borne in mind that due to illness and treatment, calves often lose weight, which is restored only by the 20 th day of life.

Over the years of studying different ways of managing calves, it was found that massive gastrointestinal diseases in calves can be prevented by placing the calves in an area free from adult animals. The degree of development of the disease, the outcome, and especially its occurrence, depend on the natural resistance of the organism. Considering that the newborn calf receives immunity directly through colostrum from the mother, which is determined by the health of the mother, the quantity and quality of colostrum. It was also revealed that one of the factors in the appearance of gastrointestinal diseases in newborn calves is the genetic (antigenic) incompatibility of parental pairs, which manifests itself in some violation of the formation of structures and digestive organs during the embryonic period.

Taking into consideration the above reasons for occurrence of gastrointestinal diseases in calves, the main preventive measures are also distinguished: targeted selection of 
parental pairs, maintaining rational feeding of pregnant cows, giving the calves colostrum during the first 15 minutes of life, optimal conditions for managing calves.

\section{Materials and methods}

The work was carried out on the basis of the Department of Epizootology, Microbiology and Parasitology of the Federal State Budgetary Educational Institution "Ryazan State Agrotechnological University Named after P.A. Kostychev", SBI RR "Ryazan Regional Veterinary Laboratory", JSC "Avangard" of Ryazan region, agricultural enterprises of Ryazan region.

The conditions of keeping and feeding young cattle were studied at the farm. Microclimate indicators were determined using a statistical psychrometer, a universal gas analyzer UG-2.

The distribution and peculiarities of the epizootology of strongylatosis of the gastrointestinal tract of the cattle were studied using copro-ovoscopic and larvoscopic diagnostic methods.

The test material was feces of the young cattle, which were taken from each animal individually. The studies were carried out on the day of collection of the material, after 4-10 hours. The feces were refrigerated prior to laboratory testing. To discover Strongylata eggs and larvae of the gastrointestinal tract in the feces of the young cattle, the methods of sequential washing, Fulleborn and Berman-Orlov were used. The types of helminths and Eimeria were determined, guided by veterinary medical parasitology, edited by J. Boch, R. Supperer (1977).

To diagnose infectious diseases of calves caused by pathogenic enterobacteria, the results of epizootological data, clinical picture, pathological and bacteriological data were used in accordance with "Guidelines for bacteriological diagnosis of colibacillosis (colibacillosis) in animals" (M., 2000); "Laboratory diagnostics of salmonella in humans and animals, the detection of salmonella in feed, food and environmental objects" (M., 1990); "Guidelines for bacteriological diagnosis of mixed intestinal infection of young animals caused by pathogenic enterobacteria" (M., 1999). During the life of animals, pathogenic enterobacteria were isolated from the contents of the intestines of calves, swabs from the mucous membranes of the oral and nasal cavities. After death, pieces of parenchymal organs, tubular bone, and intestinal areas were examined.

To clarify the diagnosis of diseases of the digestive system of the young cattle, sanitarymycological and mycotoxicological studies of feed from agricultural enterprises of 0Ryazan region were carried out using enzyme immunoassay.

\section{Results and discussion}

The analysis of the epizootic situation in agricultural enterprises of Ryazan region was carried out taking into consideration the data of veterinary reports.

Of the total number of 168,572 calves, the number of animals being sick with diseases of the digestive system was $28,32-44,19 \%$, the number of animals up to 10 days old was $6,84-13,24 \%$, that of up to 30 days old was $5,94-9,25 \%$ and that of older than 30 days was $5,20-7,36 \%$. The share of diseases of the digestive system is $48,02-59,56 \%$ in the structure of all diseases of calves. In 201019,092 animals fell ill, which was 48,02\% of the total number of diseases. The share of diseases of the digestive system in Ryazan district was $57,63-73,66 \%$, including calves under 10 days of age $(37,04-44,37 \%)$. The share of diseases in other districts was as follows: Ryazhskiy district $(52,70-75,02 \%$ and $54,52-$ $59,70 \%)$, Shatskiy district $(33,39-50,26 \%$ and $43,32-50,26 \%)$, respectively. 
Infection of animals with nematodes occurs on unfavorable pastures containing pathogens. When preparing silage from grass from such pastures, eggs and larvae practically do not die, which means that infection can also occur. In the premises for the larvae, unfavorable conditions are recognized, which consist of the destructive effect of urine on them, insufficient air in dense layers of manure, therefore, when stall management, animals become infected with helminths less often.

Sick animals, being parasitic carriers, release feces containing Strongylata eggs into the environment, thereby invading it. The survival rate of larvae in the external environment depends on various factors: the structure and composition of the soil, the shape and physical state of animals' excrement (invasive larvae do not develop in dried feces). Adult animals, being parasitic carriers, infect young animals.

As a result of the studies in the districts of Ryazan region (Ryazan, Rybnovskiy), it was found that brown stomach worms, esophagostomas, Bunostomum trigonocephalum and Chabertia were more often recorded in the young cattle up to 6-8 months of age. Moreover, the number of parasites increased from 10,5 to $16,3 \%$ with the age of the animal, which can be explained by grazing of animals on unfavorable pastures. Also, Eimeria in combination with nematodes (brown stomach worms, esophagostomas) were identified in calves aged 23 months. Calves aged 6-8 months had the highest rates of infestation with brown stomach worms in spring (April) - 23\%, in summer (August) - 18,5\% and in autumn (October) $14,9 \%$. In winter and early March, a decline in invasion was noted (EI - 10,8-12,3\%) as a result of weak activity of larvae (state of hypobiosis).

In spring, as a result of a decrease in general resistance in animals, the development of Ostertagiosis is noted, and the larval stages of the parasite inhibited in the body become more active. During the summer period, a huge number of Strongylata larvae of new generations accumulate in the external environment, which causes a large number of infected animals in late summer and autumn.

Among mixed invasions in young cattle up to 6-8 months of age, brown stomach worms were recorded in combination with Chabertia and esophagostomas, and among calves up to 2-3 months old, these parasites and Eimeria were determined.

Diseases of the digestive system are observed in young animals of different age groups: newborns, weaners, rearing and fattening calves.

Diseases of the digestive system dominated $(6,84-13,24 \%)$ in the structure of the general pathology of calves under 10 days of age. The data on the incidence of diseases of the digestive system are consistent with similar studies in other regions of the country, accounting for more than $90,0 \%$ in livestock farms in various regions of the Russian Federation $[9,10]$.

Among infectious pathologies, diseases of a bacterial nature account for $89,69-94,11 \%$ (4,95\% - salmonellosis, 50,98\% - colibacillosis, $11,92 \%$ - proteus infection, $0,47 \%$ klebsiellosis, 4,53\% - pasteurelliosis, 5,93\% - pseudomonosis, 2,10\% - staphylococcosis, $10,51 \%$ - streptococcosis).

Pathogenic enterobacteria causing diseases of the digestive organs of calves are represented by isolates of S. dublin $(14,42 \%)$, S. typhimurium $(4,81 \%)$, S. enteritidis $(3,85 \%)$, E. coli: O86:A20 (6,73\%), O26:A20 (4,81\%), O86:F41 (4,81\%), O20:K99 (2,88\%), O9:A20 (0,96\%), O26:F41 (0,96\%), O78:K99 (0,96\%), O119:A20 (0,96\%), K. pneumonia $(16,35 \%)$, P. mirabilis $(9,62 \%)$, E. aerogenes $(3,85 \%)$, C. freundii $(1,92 \%)$.

The proportion of diseases of the gastrointestinal tract of calves caused by pathogenic enterobacteria in terms of the number of unfavorable points was 36,97-63,27\% (Fig. 1). 


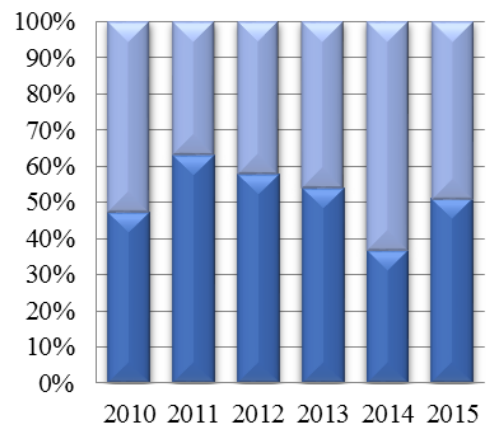

a

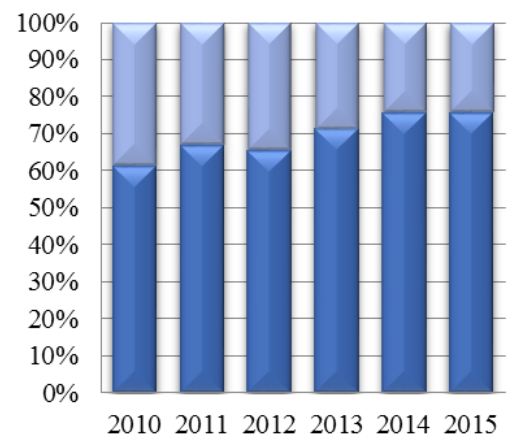

b

Fig. 1. The structure of infectious pathology: $a$ - according to the number of unfavorable points; $b$ - by the number of sick animals: - diseases of the digestive system caused by pathogenic enterobacteria.

The population at risk of susceptibility (the highest degree of potentially susceptible to disease) included calves from the neonatal period to 2-3 months. Calves from 10 days of age to 2-3 months of age were susceptible to salmonellosis with 101 cases $(95,28 \%)$; colibacillosis - predominantly the neonatal period up to 7 days old with 984 cases (90,19\%); Klebsiellosis and Proteus infection - from newborns to 27 days old with 254 cases $(99,61 \%)$ and 10 cases $(100 \%)$, respectively.

The cause of diseases of the digestive organs of the young cattle may be microscopic fungi and their metabolites - mycotoxins [5]. According to the results of laboratory data, during the analysis of sanitary and mycological studies, the infection of feed by fungi was established in $9,3 \%$ of the studied samples. Of all the studied feeds of plant origin, $37,2 \%$ of the positive results of mycological studies were in grain. During sanitary and mycological studies, microscopic fungi were found in hay, straw, haylage, silage, mixed fodder, grain, and other concentrated feed.

Of all the studied feed samples, the most affected by microscopic fungi ones were: grain - $37 \%$, other concentrated feed $-16,3 \%$ and haylage - $14 \%$, which indicates a violation of the technology of preparation and storage of the feed.

Microscopic fungi Aspergillus fumigates (smoking aspergillus), Aspergillus niger (black aspergillus), Fusarium graminearum (fusarium cereal), Fusarium sporotrichioides were determined in grain samples from Ryazan oblast farms.

According to laboratory studies carried out in 2017 in Ryazan region, no mycotoxins were found in 1,140 samples of grain, feed and pathological material taken from different farms of the region, although microscopic fungi were isolated from feed. This may indicate that laboratories test only a small number of mycotoxins. In 2018, mycotoxins were found in feed grains: zearalenone in ten corn samples and T-2 toxin in one oat sample. When analyzing epizootic data, mycotoxicosis of animals in Ryazan region were not registered.

When studying the conditions of housing and feeding, it was found that a purposeful selection of parental pairs is carried out in JSC "Avangard" to obtain healthy calves. Artificial insemination is carried out according to a plan drawn up by a livestock breeder, who selects breeding bulls for a group of cows on the basis of a plan for the development of dairy productivity of the farm, which has been followed for several years. Insemination of cows is carried out with the semen of American selection bulls: Husky of Cookiecutter line, Elwood of Mcnallan Matters line, Difference of Sandy-valley line.

Managing cows at the farm is loose, feeding is carried out according to the feed table system and each animal has the opportunity to fully satisfy its need for feed. 
The enterprise is fully supplied with all feed. The diets are fully balanced in all nutrients, as well as vitamins, macro- and microelements. The diets also have adjusted sugar-protein and calcium-phosphorus ratios.

After birth, calves are wiped with straw, tags are installed, an entry is made in the registration $\log$ and colostrum is fed within 30 minutes after birth. Colostrum for newborn calves is taken from older cows, as the number of immune bodies in the colostrum increases with age. Calves are given warm water (up to 7 liters per day) after drinking colostrum. After drying, the newborns are transferred to individual huts, which are located in a row (the distance between the houses is up to $50 \mathrm{~cm}$ ), a walking area is adjacent to each hut. The calf is kept separate from other calves, which reduces the risk of spreading infectious diseases. Straw up to $60 \mathrm{~cm}$ high is used as bedding, later it is compacted up to $15 \mathrm{~cm}$ and is constantly added. Biothermal processes occur inside the litter, which inhibit the development of microorganisms.

Calves are kept in huts for 4 months. During this time, they develop strong immunity. Each calf receives an individual approach from attendants, which allows to adjust its diet when introducing mixed fodder. Weakened calves receive more attention and increased nutrition (if necessary, colostrum is fed up to 6 times a day). After the transfer of calves to the calf shed, the huts are washed, the bedding is removed, and they are left empty for 14 days.

At the same time, it should be noted that there are negative aspects of managing and feeding pregnant cows, which in the future can cause diseases of the digestive system of young cattle.

Animals lack active exercise, which is the key to good work of the digestive process in cows, low doses of ultraviolet radiation, which affects the overall resistance of the body. Due to the loose housing of animals and concrete floors in the premises, a large accumulation of dirt is created in stables, and moisture, ammonia, carbon dioxide in the air (Table 1), which negatively affects the microclimate regime in the room, and also contributes to accumulation of opportunistic pathogens and pathogenic microorganisms in the room, and violation of the launch time leads to some reduction in the dry period and a decrease in immunoglobulins and vitamins in colostrum by 1.5 times.

Table 1. Microclimate parameters in a complex for cows in loose housing at LLC "Avangard", Ryazan District, Ryazan Region.

\begin{tabular}{|c|c|c|c|}
\hline \multirow{2}{*}{ Parameter } & \multicolumn{3}{|c|}{ Microclimate parameter } \\
\cline { 2 - 4 } & Fact & Norm & $+/-, \%$ \\
\hline Temperature, $0 \mathrm{C}$ & 10 & $8(8-10)$ & 25 \\
\hline Humidity, $\%$ & 90 & $75(65-85)$ & 20 \\
\hline Air speed, $\mathrm{m} / \mathrm{s}$ & 1 & $0,8(0,8-1)$ & 25 \\
\hline $\mathrm{CO} 2$ content, $\%$ & 0,31 & 0,25 & 24 \\
\hline NH3 content, $\mathrm{mg} / \mathrm{m} 3$ & 31 & 20 & 20 \\
\hline HS content, $\mathrm{mg} / \mathrm{m} 3$ & 6 & trace level & - \\
\hline
\end{tabular}

All microclimate parameters in the premises for keeping cows exceed the norm by an average of $20-25 \%$, while some parameters are at the maximum border in the range of permissible deviations.

\section{Conclusion}

1. The causes of diseases of the digestive system of young cattle can be helminths, protozoa, bacteria, microscopic fungi, mycotoxins.

2. Strongylatosis of the gastrointestinal tract is widespread among the young cattle in the farms of Ryazan region. 
3. Infection with strongylatosis of the gastrointestinal tract depends on the age of the animal and the extensiveness of invasion in Chabertiosis, bunostomosis and esophagostomas increases with age.

4. The highest rates of infection with Ostertagias in the young cattle up to 6-8 months old were in spring (April), summer (August) and autumn (October).

5. Bacteriosis in livestock farms accounted for $89,69-94,11 \%$ among infectious diseases of calves. The dynamics of changes in the nosological profile was characterized by the predominance of the share of colibacillosis and Proteus infection: $2010-46,50 \%$ and $7,59 \%, 2015-58,40 \%$ and $15,97 \%$, respectively.

6. The etiological structure of diseases of the digestive system caused by pathogenic enterobacteria is represented by S. dublin microorganisms; S. typhimurium; S. enteritidis; E. coli; K. pneumonia; P. mirabilis; E. aerogenes; C. freundii.

7. The risk factors for diseases of the digestive system of the young cattle include violations of the conditions of managing animals, exceeding the standards of microclimate parameters.

\section{References}

1. M.M. Basimova, R.S. Karmaliev, Theory and practice of combating parasitic diseases, 16, 28 (2018).

2. G.M. Tunikov, I.Yu. Bystrova, N.G. Byshova, Zh.S. Mayorova, E.N. Pravdina, K.K. Kulibekov, Int. J. of Advanced Biotechnology and Research (IJABR), 10(2), 465 (2019).

3. M. Britan, K. Gerceva, E. Kiseleva, V. Kulakov, E. Saytkhanov, R. Soshkin, Int. J. of Pharmaceutical Research, 11(1), 1040 (2019)

4. L. Kashirina, K. Ivanischev, K. Romanov, E3S Web of Conferences, 176, 02001 (2020)

5. I.A. Kondakova, V.I. Levin, I.P. Lgova, Yu.V. Lomova, E.A. Vologzhanina, O.A. Antoshina, Int. J. of Adv. Biotech. and Res. 10(2), 223 (2019)

6. E.V. Pechura, I.M. Sazhaev, Questions of legal regulation in veterinary medicine, 2, 63 (2015)

7. Sh.Sh. Razikov, B.I. Khudoidodov, G.N. Karimov, Theory and practice of parasitic diseases of animals, 18 (2017)

8. A.N. Tokarev, S.V. Engashev, Helminthiasis of the cattle, Ser. Scientific thought, (Moscow, 2019)

9. M. Truszczynski, Z. Pejsak, Edycyna Weterynaryjna, 70(1), 3 (2014)

10. O. Fedosova, G. Glotova, G. Ulivanova, E. Chukhina, E3S Web of Conferences, 176, 01001 (2020) 